\title{
Identification of differentially expressed genes in a renal cell carcinoma tumor model after endostatin-treatment
}

\author{
Jens van Wijngaarden ${ }^{1}$, Karien de Rooij ${ }^{1}$, Ermond van Beek ${ }^{1}$, Hans Bernsen ${ }^{2}$, Ivo Que ${ }^{1}$, \\ Victor WM van Hinsbergh ${ }^{3,4}$ and Clemens Löwik ${ }^{1}$ \\ ${ }^{1}$ Department of Endocrinology and Metabolic Diseases, Leiden University Medical Center, Leiden, The \\ Netherlands; ${ }^{2}$ Department of Neurology, Canisius-Wilhelmina Hospital, Nijmegen, The Netherlands; \\ ${ }^{3}$ Department of Physiology, Institute for Cardiovascular Research, Vrije Universiteit Medical Center, \\ Amsterdam, The Netherlands and ${ }^{4}$ Gaubius Laboratory, TNO-PG, Leiden, The Netherlands
}

\begin{abstract}
Endostatin is a cleavage product of collagen XVIII that has shown to inhibit tumor-angiogenesis in experimental tumor models. At present, the exact molecular mechanism of action of endostatin is not completely elucidated. In this study, we wanted to identify specific target genes of endostatin. For this purpose, the human renal cell carcinoma RC-9 was subcutaneously implanted in nude mice and treated with endostatin. Tumor growth was inhibited by endostatin after 4 days of treatment. Using immunohistochemistry and the hypoxia marker pimonidazole, we demonstrate disintegration of blood vessels and hypoxia and anoxia as a result of the treatment. Hereafter, we applied the polymerase chain reaction (PCR)-based subtractive suppression hybridization (SSH) method, together with the mirror orientation selection (MOS) technique to identify specifically induced and suppressed genes after endostatin-treatment. We found eight genes to be specifically induced and 11 to be suppressed by the endostatin-treatment. Among other genes, core binding factor a-1/ osteoblast-specific factor-2 (cbfa1/osf2) was found to be specifically suppressed by endostatin. Unexpectedly, cbfa1/osf2 was found to be specifically expressed in granulocytes in the tumor, not only in the experimental RC9 tumor model, but in sections of human breast cancer as well. Since an effect of antiangiogenic therapy on granulocytes has been reported before, this might lead to new insights in the role of granulocytes in antiangiogenic therapy in general. In conclusion, the SSH-PCR implemented with the MOS-technique is a powerful tool to identify differentially expressed genes. Using these techniques, we have identified several target genes of endostatin, of which cbfa1/osf2 was found to be specifically expressed in granulocytes in the tumor.
\end{abstract}

Laboratory Investigation (2004) 84, 1472-1483, advance online publication, 26 July 2004; doi:10.1038/labinvest.3700157

Keywords: cancer; cbfa1/osf2; endostatin; granulocytes; mirror orientation selection; suppression subtractive hybridization

Angiogenesis, the formation of new blood vessels from pre-existing vasculature, is dependent on a balance between pro- and anti-angiogenic factors. Antiangiogenic factors predominate in tissues where the vasculature is quiescent. In contrast, when the balance is in favor of proangiogenic factors, angiogenesis is promoted. This process is essential for the growth of solid tumors and

Correspondence: Associate Professor C Löwik, PhD, Department of Endocrinology and Metabolic Diseases, C4-R, Leiden University Medical Center, Albinusdreef 2, 2333 ZA Leiden, The Netherlands.

E-mail: c.w.g.m.lowik@lumc.nl

Received 2 April 2004; revised and accepted 24 June 2004; published online 26 July 2004 facilitates metastasis, thereby providing a rationale for antiangiogenesis therapy in cancer $^{1,2}$ Tumor angiogenesis can be inhibited by endogenous antiangiogenic factors, which results in inhibition or even regression of tumor growth and metastasis in animals. ${ }^{3}$ One of these factors is endostatin. ${ }^{4}$

Endostatin is a cleavage product of collagen XVIII that has shown to inhibit tumor-angiogenesis in experimental tumor models. Several studies have shown the inhibition of endothelial cell proliferation and migration and endothelial cell apoptosis in vitro, ${ }^{4-8}$ and growth of tumors and metastases in vivo. ${ }^{9-11}$ In animals, endostatin causes tumor vessels to collapse, which leads to the deprivation of oxygen and nutrients and results in apoptosis and necrosis of the tumor cells. ${ }^{12,13}$ No toxic side effects have 
been observed ${ }^{4,7}$ and systemic therapy has not shown to be associated with acquired resistance. ${ }^{14}$

The results of preclinical studies on endostatin have been promising; however, the first phase I clinical trials have been disappointing. ${ }^{15-17}$ Although endostatin showed no treatment-related toxicity, no significant antitumor effect was observed. In one study, a reduction in tumor blood flow and metabolism and an increase in apoptosis in tumor and endothelial cells was observed. However, no significant relationship between these biological markers and clinical outcome could be established. ${ }^{18}$ Further preclinical studies on endostatin may lead to a better understanding of its mechanism of action and may lead to other, possibly more effective therapeutic approaches.

At present, the exact molecular mechanism of action of endostatin is not completely elucidated. Endostatin can bind to $\alpha_{5^{-}}$and $\alpha_{\mathrm{v}}$-integrins on the surface of human endothelial cells, thereby inhibiting endothelial cell function. ${ }^{19}$ Also, endostatin can bind to glypican $^{20}$ and heparin and heparan sulfate. ${ }^{21}$ It has been shown that the binding of endostatin to $\alpha_{5} \beta_{1}$-integrin on the endothelial cell surface, results in a simultaneous or subsequent interaction with a heparan sulfate proteoglycan and caveolin-1. This interaction leads to an intracellular signaling cascade, which causes a reduced migratory capacity of the endothelial cell. ${ }^{22}$ Furthermore, endostatin has also shown to modulate VEGF and Wnt signaling pathways and matrix metalloprotease-2 activation, ${ }^{23-26}$ which all play an important role in angiogenesis.

In a previous study we have shown strong inhibitory effects of endostatin on VEGF-induced migration of human umbilical vein endothelial cells (HUVECs) in vitro and on the growth of the human renal cell carcinoma RC-9 in vivo. ${ }^{6}$ After subcutaneous implantation of the RC-9 tumor in nude mice, we showed regression and inhibition of tumor growth after daily administration of endostatin. This effect was most pronounced after 4 days of treatment, after which the tumor volume stabilized.

In order to study the effect and mechanism of action of endostatin, we wanted to identify which genes were specifically affected by the treatment. For this purpose, the human renal cell carcinoma RC-9 was implanted in nude mice and treated with endostatin for 4 days, after which we applied the polymerase chain reaction (PCR)-based complementary DNA (cDNA) suppression subtractive hybridization (SSH) technique. ${ }^{27}$ The SSH-technique compares two messenger RNA (mRNA) populations and identifies differentially expressed genes in one population. Furthermore, we implemented the mirror orientation selection (MOS)-technique, which significantly reduces the amount of false-positive genes. ${ }^{28}$

In the current work, we show that the endostatintreatment results in an effective inhibition of tumor growth, by causing disintegration of blood vessels, thereby generating hypoxia and anoxia, leading to tumor cell death. Hereafter, applying the SSHtechnique implemented with the MOS-technique, we found several genes to be specifically induced and several to be suppressed after the endostatintreatment. In order to verify differential expression, we studied the histological expression of calpain-2, found to be induced and core binding factor a-1/ osteoblast-specific factor-2 (cbfa1/osf2), found to be suppressed after endostatin-treatment.

\section{Materials and methods}

\section{Cell Lines, Mice and Intratumoral Injection}

The cell line RC-9 is derived from a patient with renal cell carcinoma in an advanced stage, which forms a solid tumor when transplanted in nude mice. Selected RC-9 tumor pieces of $1 \mathrm{~mm}^{3}$ were subcutaneous implanted into the right flank of halothane-anesthetized 6-week-old BALBc nu/nu mice. The human mammary carcinoma cell line MDA-MB-231 was obtained from the American Type Culture Collection (Rockville, MD, USA). Cells were cultured in Dulbecco's modified Eagle's medium (Biochrom, Basel, Switzerland), 10\% fetal bovine serum, and penicillin/streptomycin (p/s, Life Technologies, Breda, the Netherlands) in a humidified incubator at $37^{\circ} \mathrm{C}$ at $5 \% \mathrm{CO}_{2}$. For in vivo injections, cells were grown until 90\% confluency and dissociated using $0.125 \% \mathrm{w} / \mathrm{v}$ trypsin, $0.05 \% \mathrm{w} / \mathrm{v}$ ethylenediaminetetraacetic acid (EDTA) solution in PBS (pH 7.2). Hereafter, $2 \times 10^{6}$ cells $/ 100 \mu$ l PBS/ $10 \%$ FCS were injected subcutaneously in the right flank of halothane-anesthetized 6-week-old BALBc $\mathrm{nu} / \mathrm{nu}$ mice. After approximately 3 weeks, mice having tumors with a volume of $100 \mathrm{~mm}^{3}$ were selected and divided into two groups. Tumor volume was assessed by measuring the two major diameters with a caliper and using the formula: tumor volume $=\pi / 6(\mathrm{~d} 1 \times \mathrm{d} 2)^{1 / 2}$. The treatment started when the tumor volume was approximately $250 \mathrm{~mm}^{3}$. Recombinant human endostatin was obtained from B Olsen (Harvard, Boston, USA) and was purified for in vivo use in mice as described earlier. ${ }^{6}$ Mice bearing RC-9 tumors received daily injections around the tumor of $2 \mu \mathrm{g}$ human endostatin in phosphate-buffered saline (PBS) during 4 days. The control group received injections of PBS alone. Mice bearing MDA-MB231 tumors received daily injections around the tumor of $200 \mu \mathrm{g}$ endostatin as previously described. ${ }^{29}$ After treatment, tumors were surgically removed and animals were killed. Tumors were cut in half, where one half was used for RNA isolation and one for immunohistochemistry. For RNA isolation, tumors were suspended in $2 \mathrm{ml} 4 \mathrm{M}$ guanidinium isothiocyanate lysis buffer and stored at $-80^{\circ} \mathrm{C}$ until further use. For immunohistochemistry, the tumors were fixed in zinc-Macrodex formalin (ZnMF) fixative $(0.1 \mathrm{M}$ 
Tris acetate ( $\mathrm{pH} 4.5)$ containing $0.5 \%$ zinc-acetate, $5 \%$ dextran, and 10\% formalin) overnight at room temperature.

\section{Immunohistochemistry}

After overnight fixation, tissue was washed three times with PBS and subsequently processed for paraffin embedding. Human bone sections were decalcified in $5 \%$ sodium EDTA for 5 days at $4^{\circ} \mathrm{C}$ prior to paraffin embedding, as previously described. ${ }^{30}$ Immunohistochemistry was performed on $5 \mu \mathrm{m}$ of ZnMF-fixed paraffin-embedded sections. Sections were rehydrated and washed with PBS, followed by incubation with $40 \%$ methanol/1\% $\mathrm{H}_{2} \mathrm{O}_{2}$ in PBS for a half an hour at room temperature to block endogenous peroxidase activity. After washing with PBS, the sections were incubated with $5 \mu \mathrm{g} / \mathrm{ml}$ proteinase $\mathrm{K}$ in $100 \mathrm{mM}$ Tris $\mathrm{pH} \mathrm{8.0/}$ $50 \mathrm{mM}$ EDTA pH 8.0 for antigen-retrieval. Thereafter, sections were washed twice with PBS, once with $0.1 \mathrm{M}$ Tris-buffered saline ( $\mathrm{pH}$ 7.4) containing $0.02 \%$ Tween 20 (TNT) and blocked with $0.5 \%$ Boehringer milk protein (BMP) (Boehringer, Mannheim, Germany) in TNT for $1 \mathrm{~h}$ at $37^{\circ} \mathrm{C}$. This was followed by overnight incubation at $4^{\circ} \mathrm{C}$ with the primary antibody, diluted in BMP/TNT. The mousespecific rat monoclonal antibody ER-MP12/CD31 that binds to PECAM-1 was kindly provided by Dr P Leenen (Erasmus University of Rotterdam, The Netherlands). The mouse-specific rat monoclonal macrophage antibody F4/80 was a kind gift from Dr P Nijweide (Department of Molecular Cell Biology, Leiden University Medical Center, Leiden, The Netherlands). The mouse-specific rat monoclonal granulocyte antibody RB6-8C5 that reacts with Ly6G, (also designated GR-1), was purchased from Pharmingen (Alphen aan den Rijn, The Netherlands). The goat polyclonal antibody calpain-2 that binds the large subunit of calpain-2 and the rabbit polyclonal antibody PEBP $2 \alpha \mathrm{A}(\mathrm{M}-70)$ that binds to PEBP $2 \alpha \mathrm{A}$, (also designated Cbfa1, Osf2 and AML3), were purchased from Santa Cruz Biotechnology (Heerhugowaard, The Netherlands). After three washes with TNT, the sections were then incubated with biotinylated secondary antibody diluted in $\mathrm{BMP} / \mathrm{TNT}$ for $45 \mathrm{~min}$ at $37^{\circ} \mathrm{C}$, followed by incubation with horseradish (HRP)-conjugated streptavidin (Amersham Pharmacia Biotech) diluted in BMP/ TNT for $30 \mathrm{~min}$ at $37^{\circ} \mathrm{C}$. The signal was then amplified using biotinylated tyramids as described, ${ }^{31}$ followed by incubation with streptavidin-HRP and final detection by the chromogen 3amino-9-ethyl-carbazole (AEC), (Sigma Chemicals, Zwijndrecht, The Netherlands). The sections were counterstained with Mayer's Haematoxylin for $1 \mathrm{~min}$ and mounted under glass coverslips with aquamount. Representative pictures were taken with a Nikon DXM 1200 digital camera. Granulocytes were differentiated on the basis of morphology.

\section{The Hypoxia Marker Pimonidazole}

Hypoxia in the endostatin-treated tumors was determined as previously described. ${ }^{32}$ Briefly, mice were intravenously injected via one of the lateral tail veins with $0.1 \mathrm{ml}$ of a solution of saline containing $2 \mathrm{mg}$ of the hypoxia marker pimonidazole-hydrochloride. This marker was given $30 \mathrm{~min}$ before the animals were killed. For further analysis, four to five frozen sections ( $5 \mu \mathrm{m}$ thick) through central and peripheral tumor areas were prepared. Hereafter, sections were fixed in acetone and incubated overnight with rabbit antisera to pimonidazole adducts. The sections were then incubated with a fluorescent antibody and analyzed for the hypoxia signal using fluorescence microscopy.

\section{RNA and mRNA Isolation}

RNA was isolated from a control and endostatintreated RC-9 tumor according to the method described by Chomczynski and Sacchi. ${ }^{33}$ In brief, RC-9 tumors were homogenized in $2 \mathrm{ml}$ lysis buffer, extracted with phenol and chloroform, precipitated at $-20^{\circ} \mathrm{C}$ with $100 \%$ isopropanol, resuspended in autoclaved denatured water, and stored at $-80^{\circ} \mathrm{C}$. RNA concentration was determined spectrophotometrically assuming $40 \mu \mathrm{g} / \mathrm{ml}$ per optical density at a wavelength of $260 \mathrm{~nm}$ (1 cm path length). mRNA was isolated from control and endostatin-treated RC-9 tumor RNA samples by using the Dynabeads mRNA Purification Kit in accordance with the manufacturer's instructions (Dynal AS, Oslo, Norway).

\section{SSH and the MOS Technique}

SSH was performed using the PCR-Select ${ }^{\mathrm{TM}} \mathrm{cDNA}$ Subtraction Kit (Clontech, Heidelberg, Germany). In this experiment, a forward and a reverse subtraction was performed. In the forward subtraction, mRNA of a control RC-9 tumor was referred to as tester and mRNA of an endostatin-treated RC-9 tumor as driver, and vice versa in the reverse subtraction. In addition, a control provided in the kit was included. cDNA was synthesized from both RC-9 mRNA samples and the control from the kit (human skeletal muscle mRNA) in accordance with the manufacturer's instructions. The cDNA of the RC-9 tumor samples and the control skeletal muscle cDNA were digested with $R s a \mathrm{I}$ for $1.5 \mathrm{~h}$ at $37^{\circ} \mathrm{C}$. Hereafter, digested RC-9 tumor samples were divided in a tester and a driver sample. To produce a control tester, $0.2 \%$ HaeIII digested $\varphi \mathrm{X} 174$ DNA was mixed with $1 \mu \mathrm{l}$ of the skeletal muscle cDNA. The tester samples were ligated with two cDNA adaptors. To verify a ligation efficiency of at least $25 \%$, a ligation efficiency test was performed, according to the manufacturer's instructions. Subsequently, two hybridizations were performed. In the first hybridization, an excess of driver was added to each tester 
sample. The samples were heat denatured for $1.5 \mathrm{~min}$ at $98^{\circ} \mathrm{C}$ and allowed to hybridize for $8 \mathrm{~h}$ at $68^{\circ} \mathrm{C}$. The second hybridization consisted of adding freshly denatured driver cDNA to the two first hybridization samples. The samples were incubated overnight at $68^{\circ} \mathrm{C}$. From hereon, the SSH-protocol was implemented with the MOStechnique as described by Rebrikov et al. ${ }^{28}$ Briefly, each sample was divided into 10 independent samples and a 30-cycle primary PCR was performed. The 10 independent samples were then combined and a 12-cycle secondary PCR was performed using the same primer and conditions as the primary PCR. A nested PCR was performed with primers as described. The samples were then phenol/chloroform extracted and ethanol precipitated and adaptors were removed by $\mathrm{XmaI}$ digestion. Another hybridization was performed using freshly denatured driver and a final PCR was performed.

\section{DNA Cloning}

The differentially expressed sequences of the forward and reverse subtraction were cloned into a $\mathrm{pCR}{ }^{\mathbb{R}} \mathrm{II}$ vector using the TA cloning kit (Invitrogen, Groningen, the Netherlands). Two different concentrations of the PCR products, 0.5 and $1.5 \mu \mathrm{l}$, and $50 \mathrm{ng}$ vector were used in the ligation reaction. Subsequently, $2 \mu \mathrm{l}$ of each reaction was added to TOP10F' cells and incubated on ice for $30 \mathrm{~min}$. The samples were subjected to a heat shock of $30 \mathrm{~s}$ at $42 \mathrm{C}, 250 \mu \mathrm{l}$ of SOC medium was added and the samples were incubated at $37^{\circ} \mathrm{C}$ for $1 \mathrm{~h}$. Of each sample 10 and $25 \mu \mathrm{l}$ were plated on Luria Bertani (LB) plates containing $50 \mu \mathrm{g} / \mathrm{ml}$ ampicillin (Roche Diagnostics $\mathrm{GmbH}$, Mannheim, Germany), $42 \mu \mathrm{l}$ IPTG $(20 \mathrm{mg} / \mathrm{ml}$ ) (Gibco/BRL Life Technologies), and $80 \mu \mathrm{l} \mathrm{X-Gal}(20 \mathrm{mg} / \mathrm{ml})$ (Gibco/BRL Life Technologies). The plates were incubated overnight at $37^{\circ} \mathrm{C}$. The white colonies were picked and the inserts were amplified in a PCR using M13 primers (Gibco/BRL Life Technologies). The PCR products were purified using Microspin S-300 HR columns (Amersham Pharmacia Biotech). The purified PCR products were analyzed for differential expression by Southern blotting. Differentially expressed PCR products were sequenced by the Leiden Genome Technology Center (LGTC). The sequences were compared to available sequence databases, using Basic Local Alignment Search Tool (BLAST).

\section{Southern Blotting}

For probe synthesis, a nested PCR was performed with the unsubtracted controls of the forward and reverse subtraction. The products were digested with RsaI for $2 \mathrm{~h}$ at $37^{\circ} \mathrm{C}$ and the PCR products were purified using Microspin S-300 HR columns (Amer- sham Pharmacia Biotech). Thirty ng of each product was denatured for $3 \mathrm{~min}$ at $100^{\circ} \mathrm{C}$ and added to Ready-To-Go DNA labeling beads (Amersham Pharmacia Biotech). Thereafter, $5 \mu \mathrm{l} \alpha\left[{ }^{32} \mathrm{P}\right] \mathrm{dCTP}$ was added and samples were incubated at $37^{\circ} \mathrm{C}$ for $30 \mathrm{~min}$. Unincorporated nucleotides were removed by using a ProbeQuant G-50 Micro Column (Amersham Pharmacia Biotech). Before hybridization, the probes were denatured for $5 \mathrm{~min}$ at $95^{\circ} \mathrm{C}$ and put on ice for $5 \mathrm{~min}$. For Southern blotting, $50 \mathrm{ng}$ M13 PCR product of each clone was loaded on a $1 \%$ agarose gel containing $0.5 \mu \mathrm{g}$ ethidium bromide. After running, the gels were incubated in $0.4 \mathrm{M} \mathrm{NaOH}$ twice for $15 \mathrm{~min}$. Hybond- $\mathrm{N}^{+}$membranes were incubated for $10 \mathrm{~min}$ in $\mathrm{H}_{2} \mathrm{O}$ and for $15 \mathrm{~min}$ in $0.4 \mathrm{mM} \mathrm{NaOH}$. DNA was transferred onto the membrane overnight. Hereafter, the blots were neutralized in $2 \times$ SSC for $5 \mathrm{~min}$ and incubated at $80^{\circ} \mathrm{C}$ for $30 \mathrm{~min}$. The blots were prewetted in $\mathrm{H}_{2} \mathrm{O}$ and for prehybridization, an equal volume of $2 \times$ Denhardt's hybridization mix $(6 \times$ SSC, $5 \times$ Denhardt's, $0.25 \%$ SDS, $50 \mu \mathrm{g} / \mathrm{ml}$ denatured fragmented salmon sperm DNA) was added, supplemented with $0.5 \mu \mathrm{g} / \mathrm{ml}$ denatured KS cell (a mouse osteoblast cell line) DNA. The blots were prehybridized for $2.5 \mathrm{~h}$ at $65^{\circ} \mathrm{C}$. This was followed by hybridization of the blots overnight at $65^{\circ} \mathrm{C}$ with the $\left.\alpha{ }^{32} \mathrm{P}\right]$ dCTP labeled probes of the unsubtracted control of the forward or the reverse subtraction. Thereafter, the blots were washed in $1 \times \mathrm{SSC} / 0.1 \%$ SDS for $20 \mathrm{~min}$, then in $0.3 \times \mathrm{SSC} / 0.1 \%$ SDS twice for $10 \mathrm{~min}$ and in $0.1 \times \mathrm{SSC} / 0.1 \%$ SDS for $10 \mathrm{~min}$ at $65^{\circ} \mathrm{C}$. The blots were exposed to a PhosphorImager (Molecular Dynamics, Sunnyvale, CA, USA) screen and analyzed.

\section{Statistical Analysis}

The data are expressed as mean \pm s.d. For comparing endostatin-treated RC-9 tumor volumes with control tumor volumes, a Student's $t$-test was used. A $P$-value of $<0.05$ was considered significant.

\section{Results}

\section{Effect of Endostatin on RC-9 Tumor Volume In Vivo}

In order to characterize the effect of endostatintreatment and to investigate which genes are specifically induced and suppressed after the treatment by using the SSH-PCR, RC-9 tumors were treated with endostatin or PBS. The human renal cell carcinoma RC-9 was subcutaneous implanted in BALBc nu/nu mice. When a tumor volume of approximately $250 \mathrm{~mm}^{3}$ was reached, daily injections of PBS or $0.2 \mu \mathrm{g}$ recombinant human endostatin were administered around the tumor during 4 days. This dose and duration have proven to give optimal regression in previous experiments. ${ }^{6}$ Figure 1 shows the effect of endostatin-treatment on tumor 


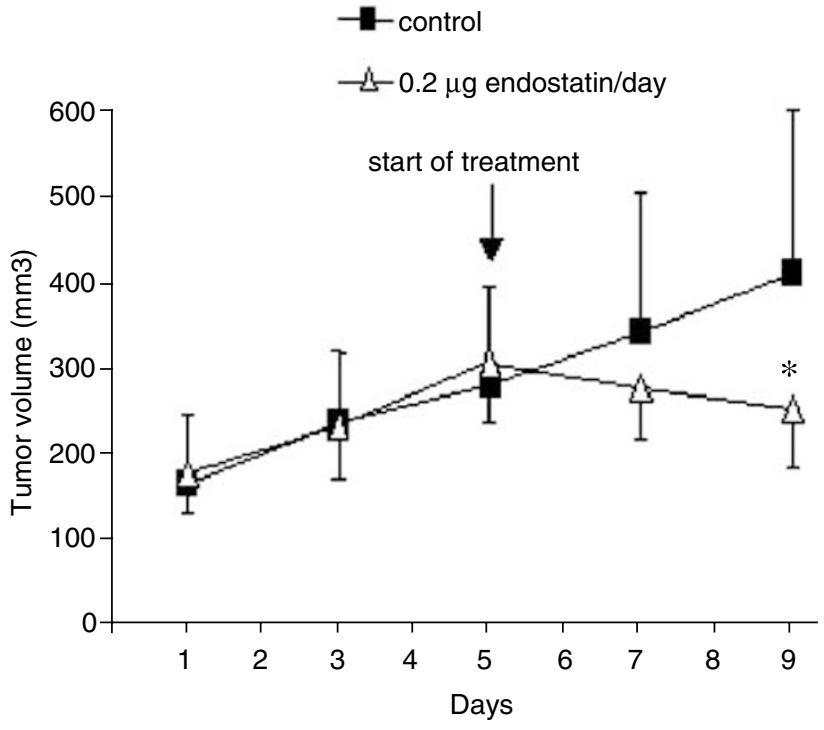

Figure 1 Effect of endostatin-treatment on RC-9 tumor growth in vivo. Effect of endostatin $(0.2 \mathrm{mg} / \mathrm{day}$, open triangles) or PBS (filled squares) treatment on the growth of RC-9 xenografts in nude mice. Treatment was started when a tumor had reached a size of $250 \pm 20 \mathrm{~mm}^{3}$. Tumor volume $\left(\mathrm{mm}^{3}\right)$ was measured as indicated in materials and methods. Values represent mean \pm s.d., $n=7$. ${ }^{*} P<0.05$ (endostatin vs control).

volume. Immediately after starting the treatment, the average tumor volume regresses compared to the control tumor volume. After 4 days of treatment, the difference in average tumor volume is significant $(P<0.05)$. At day 5 , tumors were surgically removed and prepared for immunohistochemical analysis and RNA isolation.

\section{Immunohistochemical Analysis of the Effect of Endostatin on RC-9}

To study the effect of endostatin-treatment, we stained RC-9 tumors treated for 4 days with MP12 (PECAM-1/CD31), which recognizes endothelial cells and F4/80, which recognizes mature macrophages. Figure 2a shows an MP12 staining of an endostatin-treated tumor, in which MP12 stains the anatomical vessels. Figure $2 \mathrm{~b}$ shows a F4/80 staining of an endostatin-treated tumor, in which F4/80 specifically stains tissue-macrophages. As can be seen in Figure 2a, 4-day endostatintreatment results in a necrotic center of the tumor without any vessel present (A), whereas the vessels in the outer rim of the tumor remain present after the treatment (B). Between the necrotic center and outer rim of the tumor, the vessels show a loss of integrity as indicated by discontinuation in MP12 staining (C). Figure $2 \mathrm{~b}$ shows that the necrotic center of the tumor (A) is separated from the viable outer rim of the tumor (B) by a small and distinct border containing a large quantity of tissue-macrophages (C).
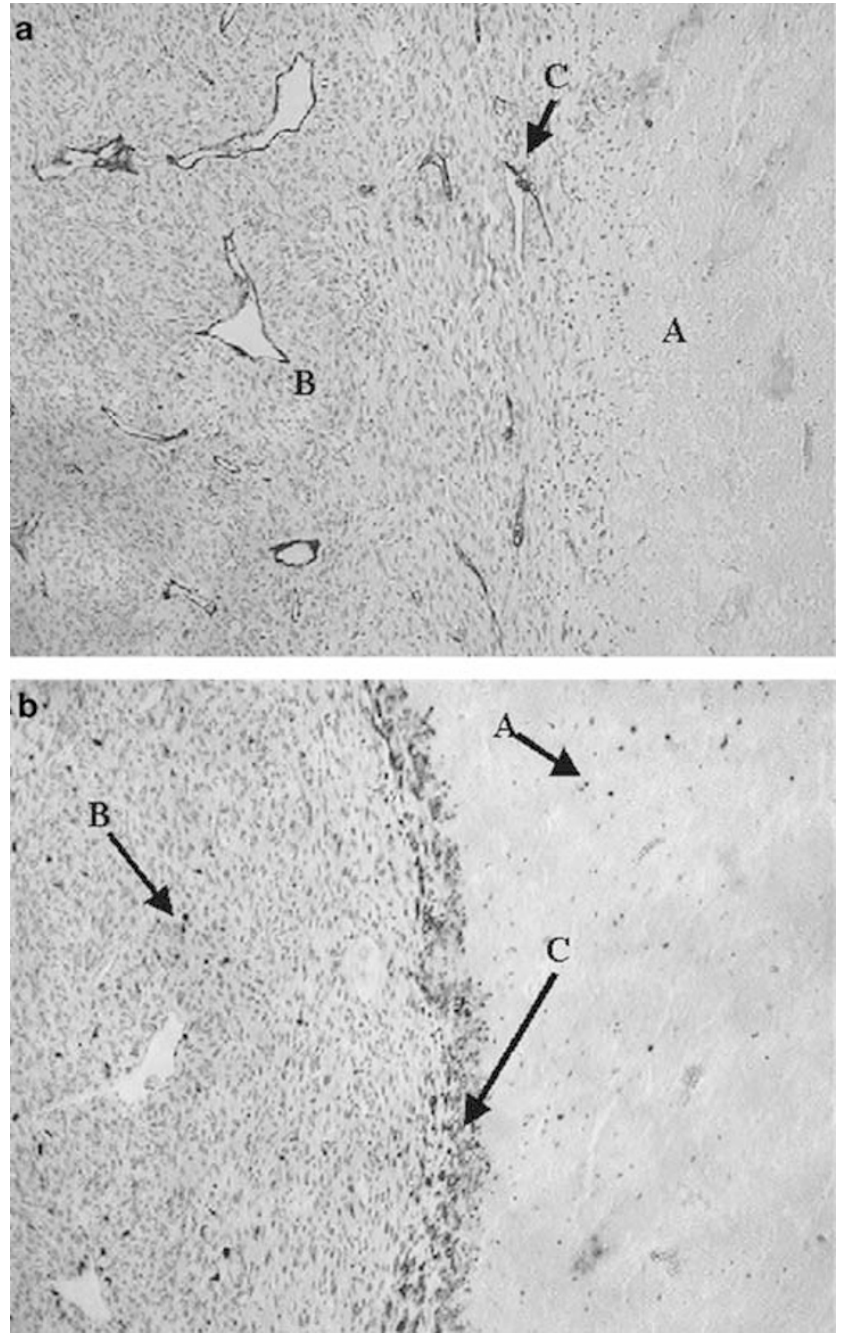

Figure 2 (a) CD31-stained histological section of an endostatintreated RC-9 tumor obtained after 4 days of treatment. (A) center of the tumor; (B) outer rim of the tumor, containing blood vessels that stain positive for CD31; (C) area around the center of the tumor containing disintegrating blood vessels. (b) F4/80-stained histological section of an endostatin-treated RC-9 tumor: (A) center of the tumor; (B) outer rim of the tumor; (C) F4/80-positive macrophages located as a ring around the center of the tumor (magnification: $\times 100$ ).

\section{Characterization of Hypoxia in Endostatin-Treated RC-9 Tumors}

In order to further characterize the effect of the endostatin-treatment on RC-9 tumors after 4 days, we used pimonidazole as a hypoxia marker. As can be seen in Figure 3a, the control RC-9 tumor shows little or no hypoxia, confirming a well-vascularized tumor. Figure $3 \mathrm{~b}$ shows the endostatin-treated tumor. The center of the tumor has no functional vasculature and therefore, no pimonidazole-positive hypoxic area is observed. The distinct ring around the necrotic center, which contains macrophages and collapsing vessels, however, is strongly hypoxic. The outer ring of the tumor, with unaffected 

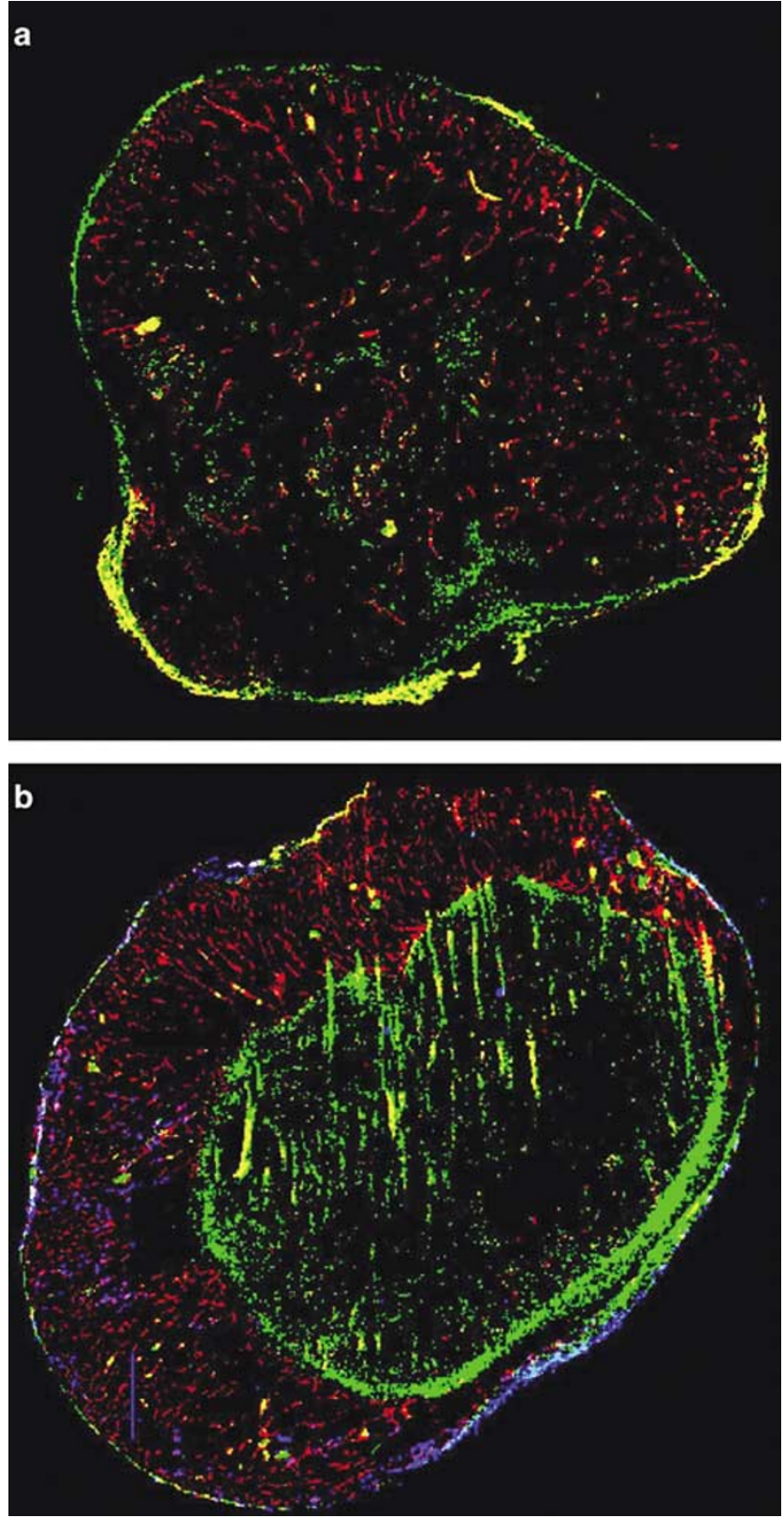

Figure 3 (a) Pimonidazole binding in a histological section of a control RC-9 tumor, as visualized by fluorescence microscopy. Hypoxic areas are indicated by green fluorescence light (magnification: $\times 40$ ). (b) Pimonidazole binding in a histological section of an endostatin-treated RC-9 tumor, as visualized by fluorescence microscopy. Hypoxic areas are indicated by green fluorescence light, (magnification: $\times 40$ ).

vessels, shows no hypoxia as visualized by the pimonidazole staining.

\section{Differential Gene Expression in RC-9 after Endostatin- Treatment}

In order to examine as to which genes are specifically induced and suppressed after the endostatintreatment, we performed an SSH using mRNA from an endostatin-treated RC-9 tumor and from a control RC-9 tumor. After performing the SSH, the obtained sequences of the forward and reverse subtraction were checked for differential expression using Southern blotting and subsequential hybridization with tester cDNA (data not shown), before sequencing. Since RC-9 is a tumor of human origin, sequences found to be differentially expressed may be human or mouse, with human sequences being exclusively expressed by tumor cells, and mouse sequences by mouse derived tissue. Table 1a shows the genes found to be specifically induced and Table $1 \mathrm{~b}$ shows the genes being specifically suppressed after endostatin-treatment in RC-9. In order to confirm differential expression, we examined the expression of an apoptosis-related gene, (calpain-2), which we found to be upregulated and a bonespecific gene (cbfa1/osf2), which was unexpectedly found to be specifically suppressed after endostatintreatment. The expression of both genes was examined at protein level, by using immunohistochemical analysis.

\section{Screening of Differential Expression of Calpain-2 in RC-9}

In order to verify the differential expression of calpain-2, we used several different control and endostatin-treated sections for immunohistochemical analysis. As can be seen in Figure 4a, control RC-9 tumors were negative for calpain-2, whereas sections of endostatin-treated RC-9 tumors stained positive for calpain-2 (Figure 4b). The positive expression was located to tumor cells.

\section{Screening of Differential Expression of $c b f a 1 / o s f 2$ in RC-9}

In order to determine the expression pattern of cbfa1/osf2, which we found to be suppressed after endostatin-treatment, sections of different control RC-9 tumors and endostatin-treated tumors were used for immunohistochemical analysis. Human bone sections were used as a positive control (Figure 5a). In these sections, osteocytes (A) and bone-lining osteoblasts (B) show a positive nuclear staining, in agreement with previous reports. ${ }^{34,35}$ The bone marrow (C) shows no staining. The expression pattern of $c b f a 1 / o s f 2$ was unexpected. Sections of control RC-9 tumors showed a positive nuclear staining of granulocytes (Figure 5b), whereas endostatin-treated tumors showed no staining (Figure 5c). Endostatin-treated RC-9 tumors did show to contain granulocytes, when sections were stained with a granulocyte-specific antibody (Figure 5d). As shown in Figure 6, the granulocytes we found to stain positive for $c b f a 1 / o s f 2$ included neutrophylic granulocytes (a), eosinophylic granulocytes (b) and basinophylic granulocytes (c). 
Table 1 (a) Induced genes and (b) suppressed genes 4 days after endostatin-treatment of RC-9

\begin{tabular}{|c|c|c|c|c|}
\hline Definition $^{\mathrm{a}}$ & Frequency ${ }^{\mathrm{b}}$ & Organism $^{\mathrm{c}}$ & E-value ${ }^{\mathrm{d}}$ & $\begin{array}{l}\text { NCBI } \\
\text { accession } \\
\text { number }^{\mathrm{e}}\end{array}$ \\
\hline \multicolumn{5}{|l|}{ (a) Induced genes } \\
\hline Expressed only in placental villi, clone SMAP83 & 3 & Homo sapiens & 0 & AB019568 \\
\hline Insulin-like growth factor binding protein-3 & 2 & Homo sapiens & $3 \mathrm{E}-65$ & X64875 \\
\hline Similar to glyceraldehyde-3-phosphate dehydrogenase & 2 & Homo sapiens & E-134 & BC013310 \\
\hline Similar to deleted in polyposis 1, clone MGC:2267 & 1 & Homo sapiens & 0 & BC000232 \\
\hline H2A histone family, member Z (H2AFZ) & 1 & Homo sapiens & E-174 & XM_052419 \\
\hline Calpain 2, (m/II) large subunit (CAPN2) & 1 & Homo sapiens & 0 & XM_010682 \\
\hline a $6.2 \mathrm{kDa}$ protein (LOC54543) & 1 & Homo sapiens & E-133 & NM_019059 \\
\hline Stearoyl-coenzyme A desaturase 1 & 1 & Mus musculus & $8 \mathrm{E}-55$ & AK012370 \\
\hline \multicolumn{5}{|l|}{ (b) Suppressed genes } \\
\hline Fibronectin & 13 & Homo sapiens & 0 & X02761 \\
\hline Chromosome 21q, section 76/105 & 2 & Homo sapiens & E-149 & AP001732 \\
\hline Chromosome 14 DNA sequence & 2 & Homo sapiens & $2 \mathrm{E}-58$ & AL137230 \\
\hline BAC R-944C7 of library RPCI-11 px19-like protein, clone MGC:15370 & 1 & Homo sapiens & 0 & BC008866 \\
\hline Tyrosine 3-monooxygenase/tryptophan 5-monooxygenase activation protein & 1 & Homo sapiens & E-139 & BC003623 \\
\hline Calmodulin 2 (phosphorylase kinase, delta), clone MGC:2168 & 1 & Homo sapiens & 0 & BC006464 \\
\hline Tubulin alpha 1, clone MGC:4760 & 1 & Homo sapiens & E-157 & ВС009513 \\
\hline Guanine nucleotide binding protein ( $\mathrm{G}$ protein), beta & 1 & Homo sapiens & 0 & ВС000366 \\
\hline Clathrin assembly lymphoid-myeloid leukemia gene & 1 & Mus musculus & 0 & BC011470 \\
\hline Osteoblast-specific factor 2 (fasciclin I-like) & 1 & Mus musculus & 0 & NM_015784 \\
\hline 10 days embryo cDNA, RIKEN full-length enriched library, clone:2610016K11 & 1 & Mus musculus & E-117 & AK011423 \\
\hline
\end{tabular}

${ }^{a}$ Definition of the sequences, as found by comparing sequenced PCR products to available sequence databases using BLAST (http:// www.ncbi.nlm.nih.gov/BLAST).

${ }^{\mathrm{b}}$ The frequency refers to the number of clones that showed homology with the identical gene found in the sequence database.

${ }^{\mathrm{c}}$ As human xenografts were used in nude mice, sequences could be reduced to human or mouse origin.

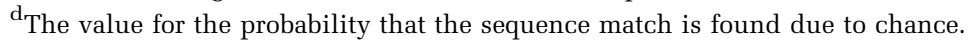

${ }^{\mathrm{e}}$ NCBI accession numbers of the defined sequences, which can be used to retrieve gene definitions at http://www.ncbi.nih.gov in the nucleotide section. All sequences shown in this table were tested for specificity using Southern blotting.

\section{Screening of Differential Expression of $\operatorname{cbfa1/osf2~in~}$ MDA-MB231}

In order to determine whether loss of cbfa1/osf2positive granulocytes was restricted to endostatintreatment in the RC-9 tumor model, we stained histological sections of endostatin-treated MDAMB231 tumors, which we found to be sensitive to endostatin-treatment as well. ${ }^{29}$ As shown in Figure 7, cbfa1/osf2-positive granulocytes were present in control MDA-MB231 tumors (a) and were absent after endostatin-treatment (b).

\section{Expression of $c b f a 1 / o s f 2$ in Sections of Human Breast Cancer}

In order to determine whether cbfa1/osf2-expression was limited to granulocytes found in the experimental RC-9 tumor model, we stained several sections of primary tumors and lymph node metastases of several patients suffering from breast cancer. We found expression of cbfa1/osf2 in granulocytes in both primary tumors (Figure 8), as well as in lymph node metastases. Positive granulocytes were found in five of the nine primary tumors and in four of the 11 lymph node metastases stained for $c b f a 1 /$ osf2. Preliminary data show no significant correlation between the expression of cbfa1/osf2 by granulocytes in primary tumors or lymph node metastases and prognosis (data not shown).

\section{Discussion}

In this study, we have shown that endostatintreatment of human RC-9 xenografts in nude mice causes disintegration of blood vessels and subsequent tumor necrosis. Using the SSH-PCR combined with the MOS-technique, we found several genes to be specifically upregulated or suppressed by the endostatin-treatment. Among others, one gene, that was found to be specifically suppressed by endostatin, was cbfa1/osf2. cbfa1/osf2 was specifically expressed in tumor-associated granulocytes.

Previous studies show that endostatin is an effective inhibitor of tumor growth in experimental tumor models. ${ }^{6,7,9-14}$ In line with these studies, we have shown that endostatin inhibits the growth of human renal cell carcinoma RC-9 xenografts in nude mice. We show that the endostatin-treatment results in disintegrating blood vessels and hypoxia and anoxia, leading to tumor necrosis. This was indicated by a loss of nuclear staining of tumor cells in the center of the tumor. Furthermore, the center area of the tumor was surrounded by a distinct rim of tissue-macrophages, most likely present to remove 

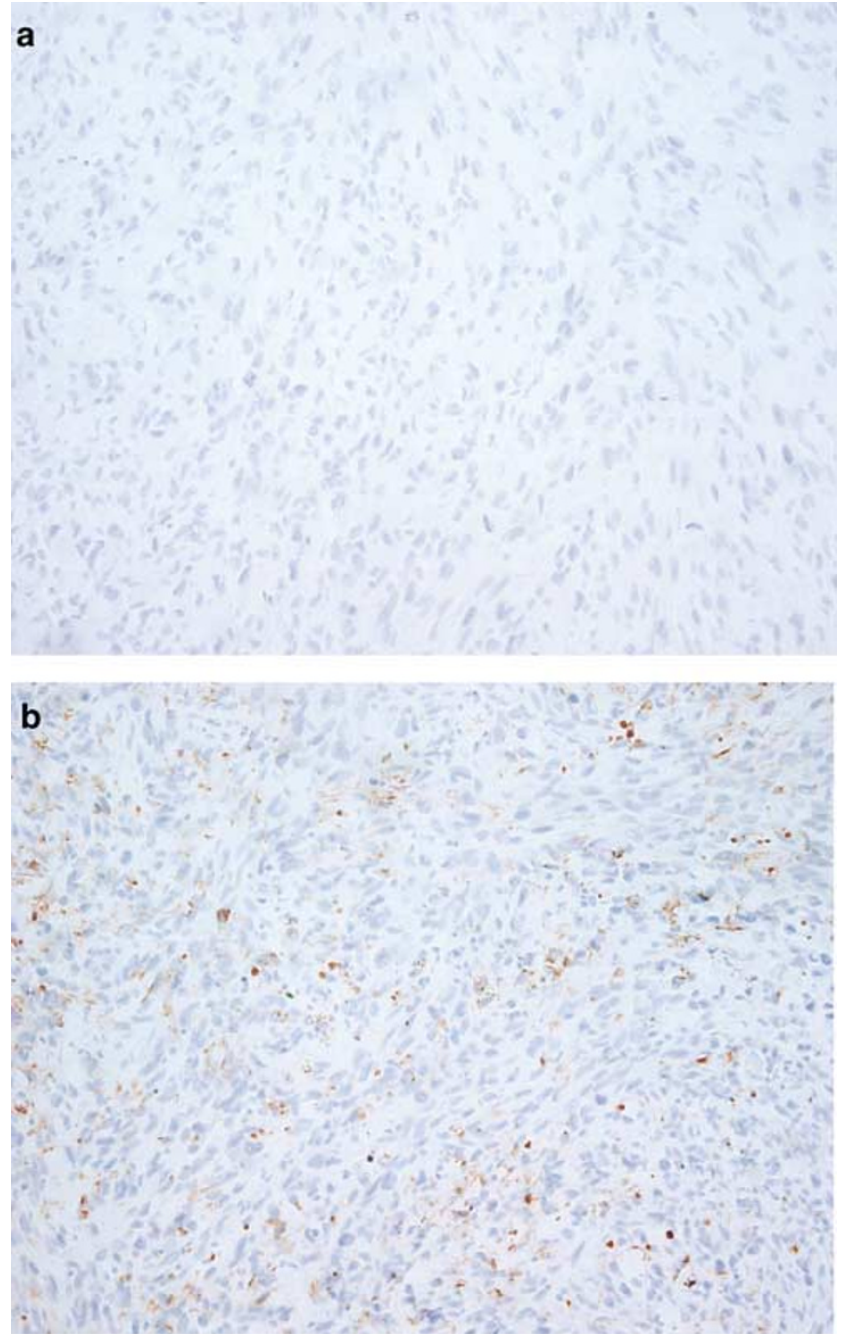

Figure 4 (a) Calpain-2-stained histological section of a control RC-9 tumor (magnification: $\times 200$ ). (b) Calpain-2-stained histological section of an endostatin-treated RC-9 tumor (magnification: $\times 200$ )

dead tissue. These observations are in concordance with previous studies, which show that endostatin can selectively induce apoptosis of tumor endothelial cells in vitro and in animals, depriving the tumor of oxygen and nutrients and resulting in tumor cell death. , $8,12,13^{-13}$

Applying the SSH-PCR technique combined with the MOS-technique, we found eight genes to be specifically induced and 11 to be suppressed by endostatin-treatment. Calpain-2 (large subunit) was among the genes that were specifically induced by the endostatin-treatment. Calpain-2 (or m-calpain) upregulation has been shown in response to a variety of apoptotic stimuli, in various cell types. ${ }^{36-39}$ It has been shown, among others, that calpain-2 mediates the cleavage of Bax, a proapoptotic protein, during drug-induced apoptosis of HL-60 cells. ${ }^{40}$ It has also been shown that calpain activation occurs after cleavage of caspase substrates and DNA fragmentation. ${ }^{41}$ In our experimental conditions, the induction of calpain-2 is likely to be the result of the tumor cell apoptosis and death induced by the endostatin-treatment.

Fibronectin is an example of a gene that was specifically suppressed after the endostatin-treatment. Fibronectin is the ligand of $\alpha 5 \beta 1$-integrin, which plays an important role in the antiangiogenic effect of endostatin. ${ }^{22}$ It has been shown that endostatin binds to $\alpha 5 \beta 1$-integrin in an RGD motifdependent manner and competes for the RGDbinding sites within fibronectin. ${ }^{42}$ The mRNA levels of fibronectin have also shown to be significantly reduced in wounds of endostatin-treated mice ${ }^{43}$ and in endostatin-treated endothelial cells. ${ }^{44}$ This is in agreement with the specifically suppressed mRNA levels of fibronectin in our model. Taken together, these data are in favor of a reduced $\alpha 5 \beta 1$-integrin interaction with fibronectin as a result of the endostatin-treatment, which may affect the migration and survival of endothelial cells and possibly the tumor cells as well.

A second gene that was specifically suppressed after endostatin-treatment, was cbfa1/osf2. cbfa1/ osf2 (or Runx-2, AML-3, PEBP2 $\alpha-A$, or $N M P-2$ ) is known as a required transcriptional regulator of osteoblast differentiation and bone formation. ${ }^{45-47}$ Therefore, our finding of $c b f a 1 / o s f 2$ expression in granulocytes in control RC-9 tumors was unexpected. cbfa1/osf2 belongs to the family of mammalian Runt-domain containing factors, consisting of three characterized factors. ${ }^{48}$ Like the two other family members, cbfa1/osf2 was first thought to play an important role in hematopoiesis. Surprizingly, few hematopoietic defects were seen in cbfa1/osf2 knockout mice. Mice embryos lacking cbfa1/osf2 had more granulocytes and fewer B cells than wildtype embryos. ${ }^{45,46}$ cbfa1/osf2 knockout mice also demonstrated extramedullary hematopoiesis in the spleen and liver due to the congenital absence of bone marrow. ${ }^{49}$ To our knowledge, this is the first report on expression of $c b f a 1 / o s f 2$ in granulocytes.

After endostatin-treatment, cbfa1/osf2-expressing granulocytes were no longer present in the tumor. Neutrophilic granulocytes have reported to be a target for the antiangiogenic effect of angiostatin, another naturally occurring inhibitor of tumor angiogenesis. ${ }^{50}$ Furthermore, it has been shown that neutrophilic granulocytes express $\alpha_{5} \beta_{1}$-integrins, which can functionally bind to fibronectin. ${ }^{51,52}$ It has been reported that endostatin can bind to $\alpha_{5} \beta_{1}$ integrins ${ }^{22}$ and we show here that fibronectin is specifically suppressed. Taken together, it is conceivable that the endostatin-treatment has an effect on granulocytes.

It is important to note that, although cbfa1/osf2positive granulocytes were absent in the tumor after endostatin-treatment, granulocytes were still present. In addition, cbfa1/osf2 expressing granulocytes were not found in bone marrow of nude mice. Whether cbfa1/osf2 expression by granulocytes is restricted to a specific subset of tumor-associated 

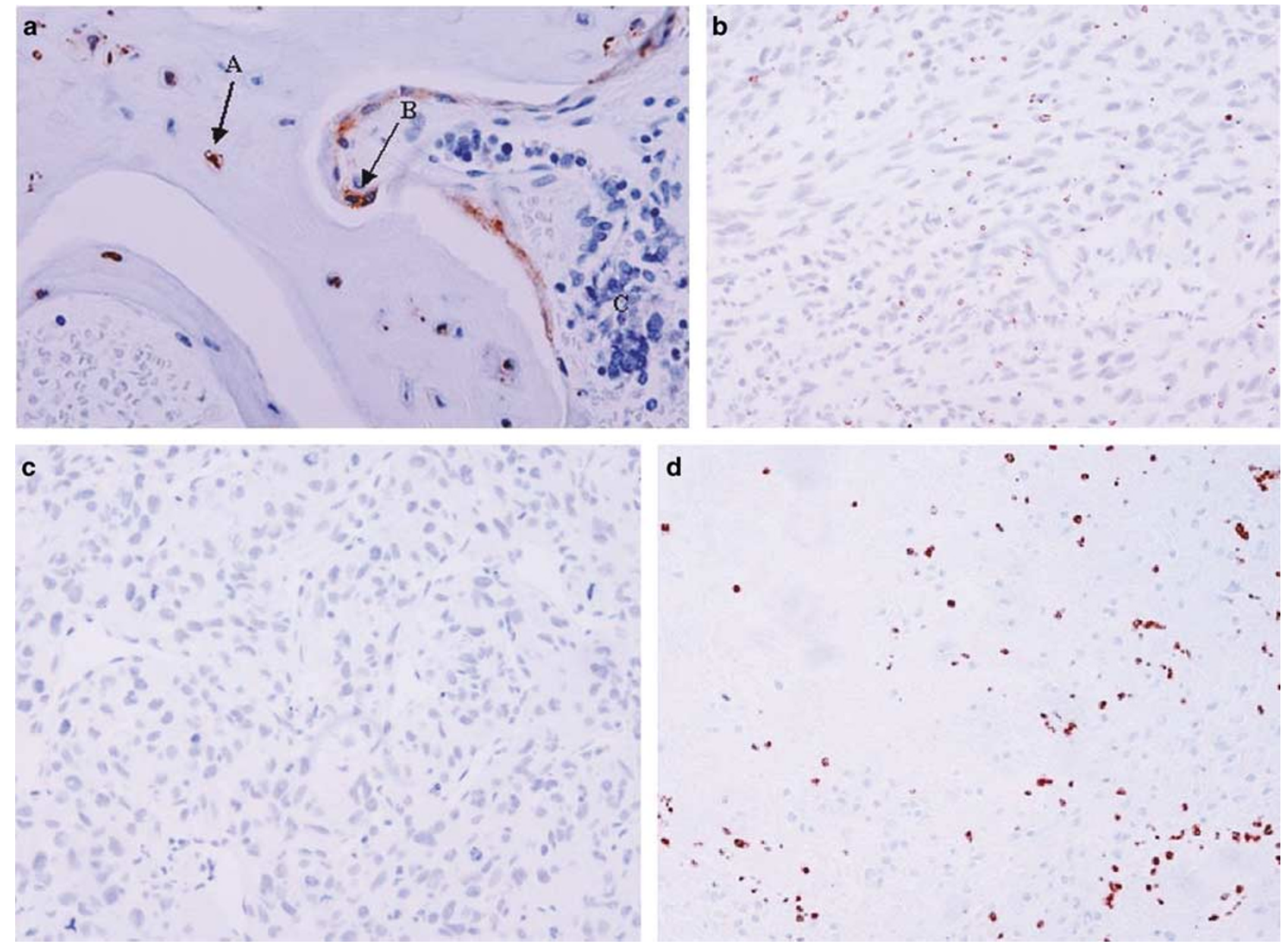

Figure 5 (a) cbfa1/osf-2-stained histological section of human bone tissue, with osteocytes (A) and bone-lining cells (B) staining positive and bone marrow $(\mathrm{C})$, which is negative (magnification: $\times 400$ ). (b) cbfa1/osf-2 stained histological sections of a control RC-9 tumor, with granulocytes staining positive (magnification: $\times 200$ ). (c) cbfa1/osf-2-stained histological sections of an endostatin-treated RC-9 tumor staining negative (magnification: $\times 200$ ). (d) Granulocytes stained with RB6-8C5 in an endostatin-treated tumor. Histological section of an endostatin-treated tumor stained with the RB6-8C5 antibody, which specifically recognizes granulocytes. Granulocytes stain positive, (magnification: $\times 200$ ).

granulocytes or granulocytes that are, for example, activated by certain inflammatory stimuli warrants further investigation.

In line with our findings in the RC-9 tumor model, cbfa1/osf2-positive granulocytes were present in nontreated MDA-MB231 tumors and were absent after endostatin-treatment. This tumor model has previously been shown to be sensitive to endostatintreatment as well. ${ }^{29}$ Taken together, this indicates that the loss of cbfa1/osf2-positive granulocytes might be a more common phenomenon in response to endostatin-treatment. Whether or not the absence of cbfa1/osf2-positive granulocytes is related to the efficacy of endostatin to inhibit tumor growth needs further investigation.

Also, we found expression of cbfa1/osf2 by granulocytes in histological sections of tumors of patients suffering from breast cancer. cbfa1/osf2positive granulocytes were both found in primary tumors as well as in lymph node metastases; however, preliminary data did not show a statistical significant correlation between cbfa1/osf2 expression in granulocytes and disease-free survival or prognosis. The finding of cbfa1/osf2-positive granulocytes in sections of patients suffering from mammary caricinoma shows that the results obtained are not restricted to experimental tumor models alone.

In summary, we have demonstrated that endostatin causes hypoxia and anoxia and tumor cell death in the mouse. Endostatin specifically induced and suppressed several genes. Among other genes, cbfa1/osf2 was specifically suppressed by endostatin. Unexpectedly, cbfa1/osf2 was expressed in granulocytes in the tumor. Since an effect of different antiangiogenic therapy on granulocytes has been reported before, this might lead to new insights in the role of granulocytes in antiangiogenic therapy in general. The mechanistic and functional role of cbfa1/osf2 in granulocytes warrants further investigation. 


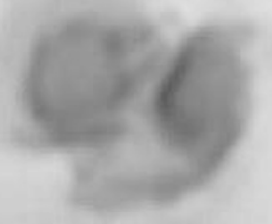

b

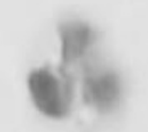

C

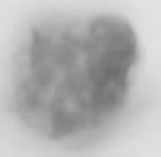

Figure 6 cbfa1/osf-2-stained histological section of a control tumor. Magnification of (a) a neutrophilic granulocyte (b) an eosinophylic granulocyte and (c) a basinophylic granulocyte (magnification: $\times 1000$ ). a
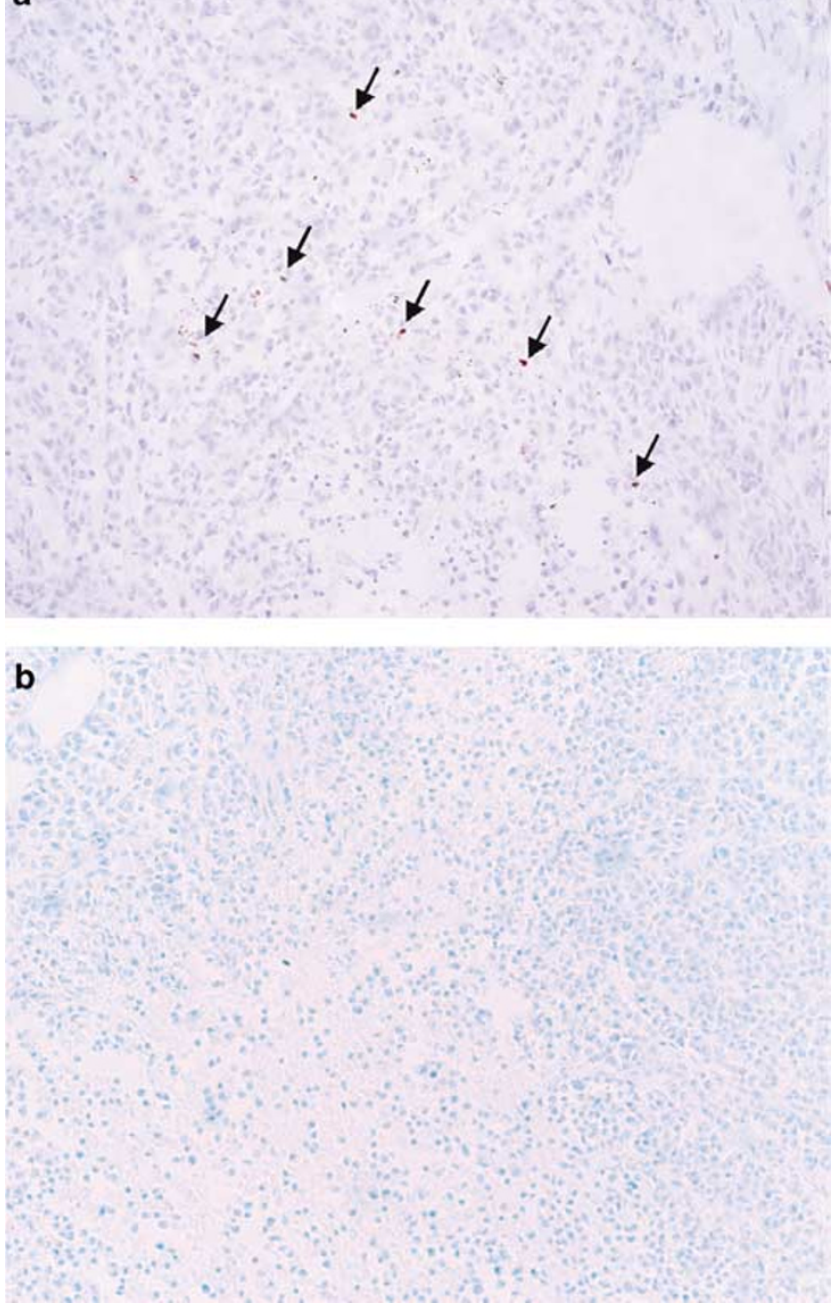

Figure 7 (a) cbfa1/osf-2-stained histological sections of a control MDA-MB231 tumor, with granulocytes staining positive (arrows indicate $c b f a 1 / o s f 2-$ positive granulocytes) (magnification: $\times 200$ ). (b) Cbfa1/osf-2 staining of an endostatin-treated MDA-MB231 tumor. Endostatin-treated MDA-MB231 tumor, staining negative for cbfa1/osf-2 (magnification: $\times 200)$.

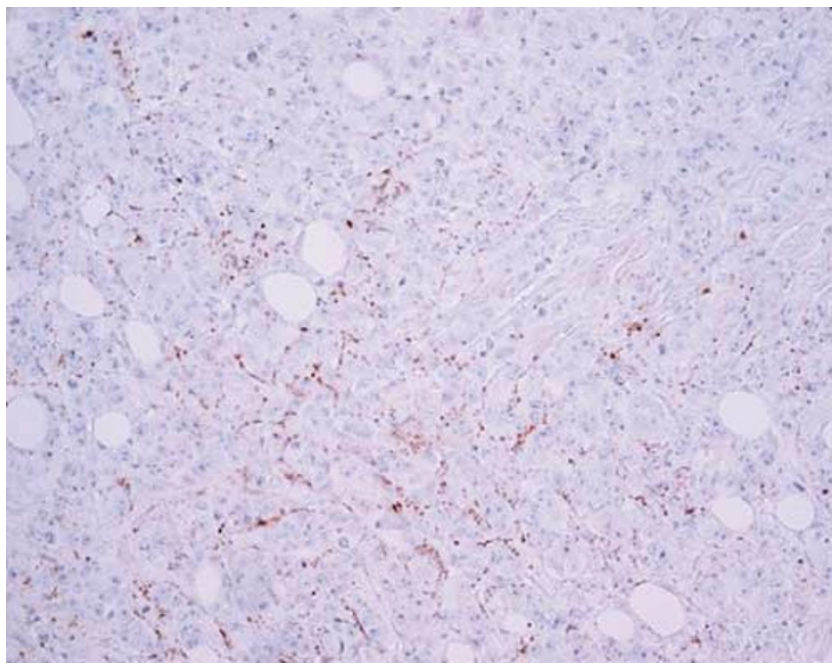

Figure 8 cbfa1/osf-2-stained histological section of human primary breast cancer (magnification: $\times 200$ ). 


\section{Acknowledgements}

This study was supported by The Netherlands Organization of Scientific Research-Medical Sciences (Grant Number: PGN 902-17-090) and by the Dutch Cancer Foundation Koningin Wilhelmina Fonds (Grant Number: RUL2000-2196).

\section{References}

1 Folkman J. Angiogenesis in cancer, vascular, rheumatoid and other disease. Nat Med 1995;1:27-31.

2 Hanahan D, Folkman J. Pattern and emerging mechanisms of the angiogenic switch during tumorigenesis. Cell 1996;86:353-364.

3 Dameron KM, Volpert OV, Tainsky MA, et al. Control of angiogenesis in fibroblasts by $p 53$ regulation of thrombospondin-1. Science 1994;265:1582-1584.

4 O'Reilly MS, Boehm T, Shing Y, et al. Endostatin: an endogenous inhibitor of angiogenesis and tumor growth. Cell 1997;88:277-285.

5 Dhanabal M, Volk R, Ramchandran R, et al. Cloning, expression, and in vitro activity of human endostatin. Biochem Biophys Res Commun 1999;258:345-352.

6 Yamaguchi N, Anand-Apte B, Lee M, et al. Endostatin inhibits VEGF-induced endothelial cell migration and tumor growth independently of zinc binding. EMBO J 1999;18:4414-4423.

7 Dhanabal M, Ramchandran R, Volk R, et al. Endostatin: yeast production, mutants, and antitumor effect in renal cell carcinoma. Cancer Res 1999;59:189-197.

8 Dhanabal M, Ramchandran R, Waterman MJ, et al. Endostatin induces endothelial cell apoptosis. J Biol Chem 1999;274:11721-11726.

9 Sauter BV, Martinet O, Zhang WJ, et al. Adenovirusmediated gene transfer of endostatin in vivo results in high level of transgene expression and inhibition of tumor growth and metastases. Proc Natl Acad Sci USA 2000;97:4802-4807.

10 Sacco MG, Cato EM, Ceruti R, et al. Systemic gene therapy with anti-angiogenic factors inhibits spontaneous breast tumor growth and metastasis in MMTVneu transgenic mice. Gene Therapy 2001;8: 67-70.

11 Blezinger $\mathrm{P}$, Wang J, Gondo $\mathrm{M}$, et al. Systemic inhibition of tumor growth and tumor metastases by intramuscular administration of the endostatin gene. Nat Biotechnol 1999;17:343-348.

12 Yokoyama Y, Dhanabal M, Griffioen AW, et al. Synergy between angiostatin and endostatin: inhibition of ovarian cancer growth. Cancer Res 2000;60:2190-2196.

13 Ding I, Sun JZ, Fenton B, et al. Intratumoral administration of endostatin plasmid inhibits vascular growth and perfusion in MCa-4 murine mammary carcinomas. Cancer Res 2001;61:526-531.

14 Boehm T, Folkman J, Browder T, et al. Antiangiogenic therapy of experimental cancer does not induce acquired drug resistance. Nature 1997;390:404-407.

15 Herbst RS, Hess KR, Tran HT, et al. Phase I study of recombinant human endostatin in patients with advanced solid tumors. J Clin Oncol 2002;20: 3792-3803.

16 Eder Jr JP, Supko JG, Clark JW, et al. Phase I clinical trial of recombinant human endostatin administered as a short intravenous infusion repeated daily. J Clin Oncol 2002;20:3772-3784.

17 Thomas JP, Arzoomanian RZ, Alberti D, et al. Phase I pharmacokinetic and pharmacodynamic study of recombinant human endostatin in patients with advanced solid tumors. J Clin Oncol 2003;21:223-231.

18 Herbst RS, Mullani NA, Davis DW, et al. Development of biologic markers of response and assessment of antiangiogenic activity in a clinical trial of human recombinant endostatin. J Clin Oncol 2002;20: 3804-3814.

19 Rehn M, Veikkola T, Kukk-Valdre E, et al. Interaction of endostatin with integrins implicated in angiogenesis. Proc Natl Acad Sci USA 2001;98:1024-1029.

20 Karumanchi SA, Jha V, Ramchandran R, et al. Cell surface glypicans are low-affinity endostatin receptors. Mol Cell 2001;7:811-822.

21 Ricard-Blum S, Feraud O, Lortat-Jacob H, et al. Characterization of endostatin binding to heparin and heparan sulfate by surface plasmon resonance and molecular modeling: role of divalent cations. J Biol Chem 2004;279:2927-2936.

22 Wickstrom SA, Alitalo K, Keski-Oja J. Endostatin associates with lipid rafts and induces reorganization of the actin cytoskeleton via down-regulation of RhoA activity. J Biol Chem 2003;278:37895-37901.

23 Kim Y, Hwang S, Kim Y, et al. Endostatin blocks vascular endothelial growth factor-mediated signaling via direct interaction with KDR/Flk-1. J Biol Chem 2002;277:27872-27879.

24 Hanai J, Gloy J, Karumanchi SA, et al. Endostatin is a potential inhibitor of Wnt signaling. J Cell Biol 2002;158:529-539.

25 Kim YM, Jang JW, Lee OH, et al. Endostatin inhibits endothelial and tumor cellular invasion by blocking the activation and catalytic activity of matrix metalloproteinase. Cancer Res 2000;60:5410-5413.

26 Lee SJ, Jang JW, Kim YM, et al. Endostatin binds to the catalytic domain of matrix metalloproteinase-2. FEBS Lett 2002;519:147-152.

27 Konietzko U, Kuhl D. A subtractive hybridisation method for the enrichment of moderately induced sequences. Nucleic Acids Res 1998;26:1359-1361.

28 Rebrikov DV, Britanova OV, Gurskaya NG, et al. Mirror orientation selection (MOS): a method for eliminating false positive clones from libraries generated by suppression subtractive hybridization. Nucleic Acids Res 2000;28:E90.

29 van der Pluijm G, Lowik C, Papapoulos S. Tumour progression and angiogenesis in bone metastasis from breast cancer: new approaches to an old problem. Cancer Treat Rev 2000;26:11-27.

30 Deckers $M$, van der Pluijm G, Dooijewaard S, et al. Effect of angiogenic and antiangiogenic compounds on the outgrowth of capillary structures from fetal mouse bone explants. Lab Invest 2001;81:5-15.

31 Kerstens HM, Poddighe PJ, Hanselaar AG. A novel in situ hybridization signal amplification method based on the deposition of biotinylated tyramine. J Histochem Cytochem 1995;43:347-352.

32 Bernsen HJ, Rijken PF, Peters H, et al. Hypoxia in a human intracerebral glioma model. J Neurosurg 2000;93:449-454.

33 Chomczynski P, Sacchi N. Single-step method of RNA isolation by acid guanidinium thiocyanate-phenolchloroform extraction. Anal Biochem 1987;162: 156-159. 
34 Geoffroy V, Corral DA, Zhou L, et al. Genomic organization, expression of the human CBFA1 gene, and evidence for an alternative splicing event affecting protein function. Mamm Genome 1998;9:54-57.

35 Komori T, Yagi H, Nomura S, et al. Targeted disruption of Cbfa1 results in a complete lack of bone formation owing to maturational arrest of osteoblasts. Cell 1997;89:755-764.

36 Squier MK, Miller AC, Malkinson AM, et al. Calpain activation in apoptosis. J Cell Physiol 1994;159:229-237.

37 Waterhouse NJ, Finucane DM, Green DR, et al. Calpain activation is upstream of caspases in radiation-induced apoptosis. Cell Death Differ 1998;5:1051-1061.

38 Xie H, Johnson GV. Ceramide selectively decreases tau levels in differentiated PC12 cells through modulation of calpain I. J Neurochem 1997;69:1020-1030.

39 Debiasi RL, Squier MK, Pike B, et al. Reovirus-induced apoptosis is preceded by increased cellular calpain activity and is blocked by calpain inhibitors. J Virol 1999;73:695-701.

40 Wood DE, Thomas A, Devi LA, et al. Bax cleavage is mediated by calpain during drug-induced apoptosis. Oncogene 1998;17:1069-1078.

41 Wood DE, Newcomb EW. Caspase-dependent activation of calpain during drug-induced apoptosis. J Biol Chem 1999;274:8309-8315.

42 Sudhakar A, Sugimoto H, Yang C, et al. Human tumstatin and human endostatin exhibit distinct antiangiogenic activities mediated by alpha $\mathrm{v}$ beta 3 and alpha 5 beta 1 integrins. Proc Natl Acad Sci USA 2003;100:4766-4771.

43 Bloch W, Huggel K, Sasaki T, et al. The angiogenesis inhibitor endostatin impairs blood vessel maturation during wound healing. FASEB J 2000;14:2373-2376.
44 Abdollahi A, Hahnfeldt P, Maercker C, et al. Endostatin's antiangiogenic signaling network. Mol Cell 2004;13:649-663.

45 Ducy P, Zhang R, Geoffroy V, et al. Osf2/Cbfa1: a transcriptional activator of osteoblast differentiation. Cell 1997;89:747-754.

46 Komori T, Yagi H, Nomura S, et al. Targeted disruption of Cbfa1 results in a complete lack of bone formation owing to maturational arrest of osteoblasts. Cell 1997;89:755-764.

47 Otto F, Thornell AP, Crompton T, et al. Cbfa1, a candidate gene for cleidocranial dysplasia syndrome, is essential for osteoblast differentiation and bone development. Cell 1997;89:765-771.

48 Westendorf JJ, Hiebert SW. Mammalian runt-domain proteins and their roles in hematopoiesis, osteogenesis, and leukemia. J Cell Biochem 1999;32-33(Suppl): 51-58.

49 Deguchi K, Yagi H, Inada $M$, et al. Excessive extramedullary hematopoiesis in Cbfa1-deficient mice with a congenital lack of bone marrow. Biochem Biophys Res Commun 1999;25:352-359.

50 Benelli R, Morini M, Carrozzino F, et al. Neutrophils as a key cellular target for angiostatin: implications for regulation of angiogenesis and inflammation. FASEB J 2002;16:267-269.

51 Frieser M, Hallmann R, Johansson S, et al. Mouse polymorphonuclear granulocyte binding to extracellular matrix molecules involves beta 1 integrins. Eur J Immunol 1996;26:3127-3136.

52 van den Berg JM, Mul FP, Schippers E, et al. Beta1 integrin activation on human neutrophils promotes beta2 integrin-mediated adhesion to fibronectin. Eur J Immunol 2001;31:276-284. 